УДК 376

\title{
РЕАБИЛИТАЦИЯ ДЕТЕЙ С РАССТРОЙСТВАМИ АУТИСТИЧЕСКОГО СПЕКТРА В ПРОЦЕССЕ СПОРТИВНО-ФИЗКУЛЬТУРНЫХ ЗАНЯТИЙ
}

\author{
Стаброва Александра Сергеевна \\ преподаватель \\ МОУ Гимназия №41
}

\begin{abstract}
Аннотация: В данной статье рассматривается проблема обучения детей с расстройствами аутистического спектра младшего школьного возраста. Раскрываются особенности обучения детей с данным расстройством, предлагаются авторские шкала оценки проявления аутистического поведения, шкала оценки навыков ребёнка, а также методические рекомендации по работе с детьми с РАС с использованием нестандартных методов спортивной реабилитации.
\end{abstract}

Ключевые слова: Расстройства аутистического спектра, РАС, роллер спорт, обучение, шкала оценки навыков, реабилитация, адаптация.

\section{REHABILITATION OF CHILDREN WITH AUTISM SPECTRUM DISORDERS IN THE PROCESS OF SPORTS AND PHYSICAL EDUCATION}

\section{Stabrova Alexandra Sergeevna}

\begin{abstract}
This article discusses the problem of teaching children with autism spectrum disorders of primary school age. The features of teaching children with this disorder are revealed, a scale for assessing the manifestation of autistic behavior, a scale for assessing the child's skills, as well as methodological recommendations for working with children with ASD using non-standard methods of sports rehabilitation are proposed.
\end{abstract}

Key words: Autism spectrum disorders, ASD, roller sports, training, skill assessment scale, rehabilitation, adaptation. 
По данным Росстата, количество детей с ОВ3 в России с каждым годом стремительно увеличивается. Школам необходимо переходить на новый уровень образовательной системы, включающей в себя инклюзивное образование и соответствующее и доступное педагогическое сопровождение детей с ОВ3. Кроме того, на ряду с различными нарушениями среди детей с особенными потребностями, одним из самых трудных для инклюзии заболеваний является аутизм.

У детей с расстройством аутистического спектра наблюдаются проблемы с социальным взаимодействием, ограниченность интересов и трудности с игровой деятельностью, стереотипность поведения, нарушение речи и вербального общения в целом, также могут наблюдаться нарушения интеллектуальных способностей; часто наблюдается отсутствие инстинкта самосохранения, нарушение координации, ощущения себя в пространстве, вследствие чего может быть нарушена походка и движения. Такие дети нуждаются в качественной комплексной реабилитации, чтобы иметь возможность социализироваться, получать образование и вести обычный образ жизни в целом.

На сегодняшний день количество таких детей повсеместно увеличивается, школы принимают все больше особенных учеников, но, к сожалению, о проблеме аутизма в России знают совсем мало. К 2021 году количество людей $\mathrm{c}$ расстройством аутистического спектра снова увеличилось, и по данным ВОЗ на 160 человек 1 приходится с данным заболеванием, а по неофициальным данным (не во всех странах официально ведется статистика по аутизму) на 59 человек приходится 1 аутист. Страшно предположить, что через пять лет каждый второй ребенок в мире будет страдать данным недугом.

Проблема аутизма в России усугубляется тем, что реабилитация и педагогическое сопровождение таких детей не доступно в должной мере. Недостаточное количество специализированных учреждений, нехватка специалистов, неэффективная реализация инклюзии - всё это снижает шансы таких детей на получение эффективной, доступной реабилитации и качественного образования.

Кроме того, что новых современных программ по реабилитации не так много, чаще всего в работе с аутистами используются обобщенные методы, которые не всегда подходят для работы с РАС. Аутизм - сложное заболевание, требующее комплексного подхода, а также определенных 
методов коррекции поведения. В такой реабилитации нужна постоянная система, особый подход, применяющийся во всех сферах данной реабилитации: социальной, физической, психологической и т.д.

$\mathrm{B}$ реабилитации детей с РАС эффективными считаются такие программы, которые включают в себя комплекс мер, направленных на поведенческую коррекцию, на предотвращение нежелательного поведения ребенка; методики, развивающие вербальные навыки коммуникации, обучающие социальному взаимодействию; методики, позволяющие также развить физические способности, особенно координацию и пространственную ориентацию.

Чтобы программа реабилитации для ребенка с РАC действовала эффективно, важно также уделять особое внимание физическому воспитанию. Так как у детей с РАС часто наблюдаются нарушение координации и проприоцепции, занятия физкультурой должны прорабатывать данные проблемы с особым вниманием. Часто положительный эффект в реабилитации дают нестандартные занятия, включение таких детей в сложно координационные виды спорта. Для эффективных спортивных занятий в своей практике мы использовали направление роллер спорта.

Прежде всего, роллер спорт - это вид активности, требующий наибольшей концентрации и работы над равновесием, это спорт, где задействуются все мышцы ног, пресса и спины, а также грудь, верхний плечевой пояс и руки. При занятиях роллер-спортом мышечный тонус значительно повышается, особенно улучшается работа мышц-стабилизаторов, которые как раз отвечают за удержание равновесия. Кроме тренировки мышц, данный спорт позволяет улучшить реакцию. Даже на самых первых этапах освоения данного вида физической нагрузки развивается выносливость и улучшается координация, что особенно важно в реабилитации детей с РАС.

Именно поэтому мы решили изучить теоретические основы проблемы аутизма у младших школьников и разработать индивидуальную программу комплексной реабилитации с применением спортивно-физкультурных практик, в том числе, занятий роллер-спортом, учитывая особенности развития детей с РАС.

Целью исследования было выявить и реализовать научно-методические основы реабилитационной программы средствами физической культуры для 
детей с РАС. Гипотеза исследования заключалась в предположении о том, что научно-методическими основами реабилита-ционной программы средствами физической культуры для детей с РАС являются:

- использование уникальных методов диагностики;

- комплексный подход, включающий в себя методы социальной, психологической и педагогической реабилитации;

- у учет физических и психических особенностей развития детей с PAC;

- использование новых методов физической реабилитации, таких как роллер-спорт;

- использование эффективных приемов из существующих методик по коррекции поведения детей с РАC;

Задачами исследования было: оценить проблемы педагогического сопровождения детей с ОВ3 в условиях современного образования; изучить сущность реабилитации детей с ОВ3; изучить теоретические основы PAC, а также особенности психического и физического развития детей с расстройством аутистического спектра; выявить наиболее эффективные методы и приёмы реабилитации детей с PAC а также разработать и реализовать индивидуальную программу реабилитации и педагогического сопровождения детей с РАС.

Для проведения исследования была подобрана группа детей с РАC, имеющих различную степень проявления аутистического поведения и различия во владении навыками. Анализ психолого-педагогической литературы по вопросу особенностей психофизического развития детей с РАС показал, что многие исследователи в области изучения аутизма подтверждают, что у всех детей данной категории существуют нарушения в области коммуникации, социальных взаимодействий, а также часто встречаются нарушения координации и пространственно-временная дезориентация. Кроме того, семьи, где есть ребенок с особенностями, также нуждаются в поддержке. В связи с этим, реабилитационные мероприятия должны быть направлены на формирование коммуникативных навыков у детей с расстройствами аутистического спектра, а также на их социальную адаптацию, обучение социальным навыкам и укреплении физического 
здоровья, при этом в реабилитации также важно участие всей семьи. Так как многие известные методы реабилитации по отдельности не всегда производят необходимый эффект, в ходе исследования теоретических данных было выявлено, что наиболее эффективным методом является комплексный подход к реабилитации с использованием не только психо-педагогических приемов, но и физкультурных практик, а также новых нестандартных направлений реабилитации.

В процессе исследования были разработаны шкала оценки проявления аутистического поведения, а также шкала оценки навыков ребёнка (рис.1 и рис.2). Данные методики оценивания были разработаны с помощью модификации известных методик ATEC, ADOS, ABC и др. Шкалы оценки были составлены с учетом следующих показателей: развития невербальных и вербальных навыков коммуникации, понимания и восприятия обращенной речи, использование и понимание социальных жестов. Также учитывались проявления аутистических признаков, как закрытость от внешнего мира, неспособность поддерживать зрительный контакт, нарушения пространственно-временного восприятия, нарушения координации и проявление стереотипного и нежелательного поведения.

Данные методы оценивания позволили наиболее подробно выявить индивидуальные образовательные потребности каждого ребёнка, а также разработать и реализовать программу реабилитации и педагогического сопровождения в процессе занятий роллер-спортом детей с РАС младшего школьного возраста. По результатам констатирующего среза было выявлено, что по общим диагностическим тестам можно условно разделит детей на три группы: с легкой формой аутизма, с средней формой проявления, с тяжелой формой аутизма. 
Шкала оценки проявления аутистнческого поведения

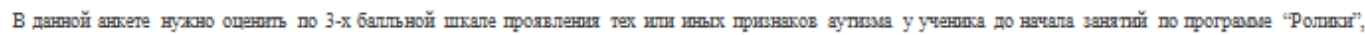

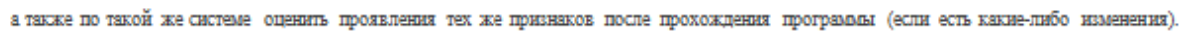

\begin{tabular}{|c|c|c|c|c|c|c|c|c|c|c|c|}
\hline & ФИО ребёнка & BoB & & $\mathrm{Mai}$ & M. & Erop & Ш. & Ди & $\Phi$. & Map & пна Б. \\
\hline \multirow[t]{2}{*}{ № } & \multirow[t]{2}{*}{ Признаки и проявления } & \multicolumn{2}{|c|}{ баллы } & \multicolumn{2}{|c|}{ баллы } & \multicolumn{2}{|c|}{ баллы } & \multicolumn{2}{|c|}{ баллы } & \multicolumn{2}{|c|}{ баллы } \\
\hline & & $\begin{array}{l}1 \text { заните } \\
\text { (ореная } \\
\text { or } 1 \text { до 10) }\end{array}$ & $\begin{array}{l}14 \text { заняте } \\
\text { (одента or } \\
1 \text { до 10) }\end{array}$ & $\begin{array}{l}1 \text { заните } \\
\text { (onessas } \\
\text { or } 1 \text { до } \\
10)\end{array}$ & $\begin{array}{l}14 \text { занвие } \\
\text { (онениа ог } \\
1 \text { до 10) }\end{array}$ & $\begin{array}{l}1 \text { занятие } \\
\text { (орендя } \\
\text { or } 1 \text { до 10) }\end{array}$ & $\begin{array}{l}14 \text { занате } \\
\text { (оцена ов } \\
1 \text { до 10) }\end{array}$ & $\begin{array}{l}1 \text { занитае } \\
\text { (onpass } \\
\text { or } 1 \text { до } \\
10)\end{array}$ & $\begin{array}{l}14 \text { заняте } \\
\text { (опенка о7 } \\
1 \text { до 10) }\end{array}$ & 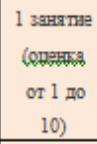 & $\begin{array}{l}14 \text { занвие } \\
\text { (опенха ог } \\
1 \text { до 10) }\end{array}$ \\
\hline 1 & $\begin{array}{c}\text { Плохой зрительный } \\
\text { контакт (Не смотрит в } \\
\text { глаза) } \\
\end{array}$ & 3 & 2 & 2 & 1 & 2 & 2 & 1 & - & 3 & 2 \\
\hline 2 & $\begin{array}{c}\text { Игнорирование } \\
\text { обращенной речи (не } \\
\text { откликаетсл, не } \\
\text { поворачивает голову на } \\
\text { звук голоса) }\end{array}$ & 3 & 2 & 2 & 1 & 2 & 1 & 1 & - & 3 & 2 \\
\hline 3 & $\begin{array}{c}\text { Боязнь громких звуков и } \\
\text { шума (часто затыкает } \\
\text { уши) }\end{array}$ & 3 & 2 & 2 & 1 & 3 & 2 & 2 & 1 & 3 & 2 \\
\hline 4 & $\begin{array}{c}\text { Отстраненность, } \\
\text { пребывание «в } \\
\text { собственном мире» }\end{array}$ & 3 & 2 & 2 & 1 & 2 & 1 & 1 & 1 & 3 & 2 \\
\hline 5 & $\begin{array}{c}\text { Oтсутствие интереса } \mathrm{k} \\
\text { окружающему }\end{array}$ & 3 & 2 & 2 & 1 & 2 & 1 & 1 & - & 3 & 2 \\
\hline 6 & $\begin{array}{c}\text { Проявление } \\
\text { нежелательного поведения } \\
\text { (продолжительная } \\
\text { истерика, когда что-то } \\
\text { делают не так, как хочет) }\end{array}$ & 2 & 1 & 3 & 2 & 1 & 1 & 1 & - & 2 & 1 \\
\hline 7 & $\begin{array}{c}\text { Негативная реакция на } \\
\text { прикосновения (к волосам, } \\
\text { к телу, к голове) }\end{array}$ & 3 & 2 & 3 & 2 & 2 & 1 & 2 & 1 & 3 & 2 \\
\hline 8 & $\begin{array}{l}\text { Тревожность в людных } \\
\text { местах }\end{array}$ & 3 & 2 & 1 & 1 & 2 & 1 & 2 & 1 & 3 & 2 \\
\hline 9 & $\begin{array}{l}\text { Стереотипное поведение } \\
\text { (хлопанье руками, } \\
\text { кручение пальцами или др. } \\
\text { формы самостимуляции) }\end{array}$ & 2 & 1 & 3 & 2 & 2 & 1 & 1 & - & 3 & 2 \\
\hline 10 & Гиперактивность & 3 & 1 & 3 & 1 & 1 & 1 & 2 & 1 & 3 & 2 \\
\hline 11 & $\begin{array}{l}\text { Частые перепады } \\
\text { настроения }\end{array}$ & 3 & 2 & 2 & 2 & 1 & 1 & 3 & 2 & 1 & 1 \\
\hline & & 31 & 19 & 26 & 15 & 20 & 13 & 17 & 7 & 30 & 20 \\
\hline
\end{tabular}

\section{1-17 баллов - лёгкая форма}

18-24 - средняя форма

25-33 - тяжелая форма

\section{Рис. 1. Шкала оценки проявления аутистического поведения}


Шкала оценки навыков ребенка

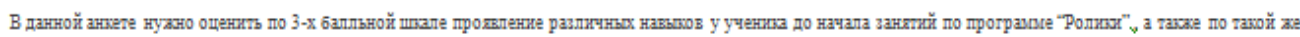

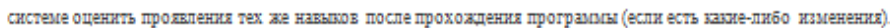

\begin{tabular}{|c|c|c|c|c|c|c|c|c|c|c|c|}
\hline \multirow{3}{*}{ № } & ФИО ребёнка & Вова & & Май & M. & Erop & Ш. & Дим & $\Phi$. & Mapr & пна Б. \\
\hline & \multirow[t]{2}{*}{ Навыгк } & \multicolumn{2}{|c|}{ баллы } & \multicolumn{2}{|c|}{ баллы } & \multicolumn{2}{|c|}{ баллы } & \multicolumn{2}{|c|}{ баллы } & \multicolumn{2}{|c|}{ баллы } \\
\hline & & 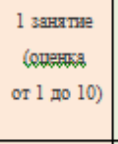 & $\begin{array}{l}14 \text { занвие } \\
\text { (оденга ог } \\
1 \text { до 10) }\end{array}$ & $\begin{array}{l}1 \text { занатие } \\
\text { (ореная } \\
\text { or } 1 \text { до } \\
10)\end{array}$ & $\begin{array}{l}14 \text { зантие } \\
\text { (оденга оz } \\
1 \text { до 10) }\end{array}$ & 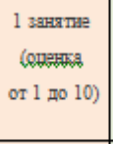 & $\begin{array}{l}14 \text { зангпе } \\
\text { (оденка оz } \\
1 \text { до 10) }\end{array}$ & $\begin{array}{c}1 \text { занятाе } \\
\text { (орентs } \\
\text { or } 1 \text { до } \\
10)\end{array}$ & $\begin{array}{l}14 \text { зангие } \\
\text { (оненпа оz } \\
1 \text { до 10) }\end{array}$ & $\begin{array}{c}1 \text { занятие } \\
\text { (ораняя } \\
\text { or } 1 \text { до } \\
10) \\
\end{array}$ & $\begin{array}{l}14 \text { зансте } \\
\text { (оценга о? } \\
1 \text { до 10) }\end{array}$ \\
\hline 1 & $\begin{array}{c}\text { Понимание голосовых } \\
\text { инструщцй } \\
\end{array}$ & 1 & 2 & 2 & 3 & 2 & 3 & 3 & 3 & 1 & 2 \\
\hline 2 & Понимание жестов & 1 & 2 & 2 & 3 & 2 & 3 & 2 & 3 & 1 & 2 \\
\hline 3 & Отклик на свое имя & 2 & 3 & 2 & 3 & 2 & 3 & 3 & 3 & 1 & 2 \\
\hline 4 & $\begin{array}{c}\text { Умение называть по имени } \\
\text { другого человека }\end{array}$ & 1 & 2 & 2 & 3 & 1 & 2 & 3 & 3 & 1 & 2 \\
\hline 5 & $\begin{array}{c}\text { Умение самостоятельно } \\
\text { надевать экипировку }\end{array}$ & 1 & 3 & 1 & 2 & 1 & 3 & 2 & 3 & 1 & 2 \\
\hline 6 & $\begin{array}{c}\text { Использование вербальной } \\
\text { компуникации (может } \\
\text { сказать, что он хочет) }\end{array}$ & 1 & 2 & 2 & 3 & 1 & 2 & 3 & 3 & 2 & 3 \\
\hline 7 & $\begin{array}{c}\text { Использование } \\
\text { невербальной } \\
\text { коммуникации (может }\end{array}$ & 2 & 2 & 2 & 2 & 2 & 2 & 3 & 3 & 1 & 2 \\
\hline 8 & $\begin{array}{c}\text { Использование социальных } \\
\text { жестов приемлемьп } \\
\text { образом и в логичном } \\
\text { контексте (приветственный } \\
\text { кивок, рукопожатие или } \\
\text { др.) } \\
\end{array}$ & 1 & 2 & 2 & 3 & 2 & 3 & 2 & 3 & 1 & 2 \\
\hline 9 & $\begin{array}{c}\text { Развитое чувство } \\
\text { равновесия, координация }\end{array}$ & 1 & 3 & 2 & 3 & 1 & 3 & 2 & 3 & 1 & 2 \\
\hline 10 & Физическая выносливость & 1 & 3 & 2 & 3 & 1 & 3 & 1 & 3 & 1 & 2 \\
\hline & & 12 & 24 & 19 & 28 & 15 & 27 & 24 & 30 & 11 & 20 \\
\hline & & $\begin{array}{r}10-166 \\
17-2 \\
24-306\end{array}$ & $\begin{array}{l}\text { алов- ни } \\
3-\text { средң } \\
\text { ялов-вь }\end{array}$ & $\begin{array}{l}\text { зкий уров } \\
\text { ий уровен } \\
\text { сокий ур }\end{array}$ & $\begin{array}{l}\text { вень влад } \\
\text { нь владе } \\
\text { овень вл }\end{array}$ & $\begin{array}{l}\text { ния навь } \\
\text { я навыка } \\
\text { ения на: }\end{array}$ & $\begin{array}{l}\text { й; } \\
\text { ками. }\end{array}$ & & & & \\
\hline
\end{tabular}

\section{Рис. 2. Шкала оценки навыков ребёнка}

По результатам комплексной диагностики, о каждом ребенке составлено краткое резюме. В процессе проведения диагностического среза выявлено, что у каждого ребёнка имеются:

- проблемы с вербальной коммуникацией;

- проблемы с мелкой моторикой;

- низкий уровень использования и понимания социальных жестов;

- негативная реакция на шум и резкие звуки;

- трудности с распознаванием мимики;

- низкий уровень физической выносливости;

- быстрая утомляемость;

- проблемы с равновесием и координацией. 
Таким образом, при составлении реабилитационной программы в первую очередь необходимо было уделить внимание обстановке, в которой будут проводиться занятия; усвоению социальных жестов, вербальных способов коммуникации, а также стоит уделить внимание мелкой моторике, упражнениям на координации и равновесие. Также, важно строить занятия таким образом, чтобы дети не уставали быстро, не перенапрягались и не испытывали сильный стресс. Введение нового материала или смену обстановки нужно вводить постепенно, позволяя детям с РАС привыкнуть; для улучшения выносливости дополнять нагрузку также постепенно, увеличивая с каждым разом время занятий, сокращая время отдыха.

Помимо работы над общими показателями важно учитывать индивидуальные показания каждого ребенка и работать над развитием навыков конкретного ребенка, исходя из его слабых сторон. Комплекс игр и упражнений для детей младшего школьного возраста с расстройствами аутистического спектра, направленных на улучшение коммуникативных и социальных навыков, а также на улучшение физических показателей детей, предполагает улучшение вербальной и невербальной коммуникации, приобретение навыка обращенной речи, улучшения восприятия речи и невербальной коммуникации, а также развитие физической выносливости, улучшение координации и пространственно-временной ориентации.

Особенностью данной реабилитации является нестандартный выбор спортивного направления - роллер спорта. Краткосрочная образовательная программа «Ролики без границ» предназначена для обучающихся младшего и среднего школьного возраста с расстройством аутистического спектра. Срок реализации программы: 14 дней.

Возраст детей, которые могут принимать участие в данной программе, варьируется от 7 до 13 лет. Такой разброс связан с тем, что проявление расстройства аутистического спектра в этом возрастном промежутке у всех детей проявляется по-разному. Часто фактический возраст не соответствует уровню развития, причём, у более младших детей интеллектуальное развитие может быть выше, чем у ровесников, и наоборот. Всё зависит от индивидуального развития ребенка, от того, какие коррекционные методики используются при его обучении, а также от наличия других сопутствующих заболеваний.

Программа рассчитана на индивидуальное обучение детей с PAC с помощью занятий роллер спортом, тем самым охватывая как 
психопедагогический аспект, так и физический. На занятиях дети с РАС учатся не только осваивать новые спортивные навыки, повышают свою выносливость, силу, улучшают координацию и равновесие, но и учатся простым бытовым навыкам, как “надеть экипировку”, “застегнуть ролики” и др. Кроме того, особо важным критерием данной реабилитации является работа над улучшением коммуникативных, социальных навыков, навыков восприятия и психологической устойчивости к окружающей среде.

Для осуществления эффективных занятий необходимо обеспечить комфортные условия, начиная комфортной одеждой и заканчивая привычной атмосферой в помещении (комфортная температура, яркость света и др.). Иными словами, необходимо учесть все факторы, которые могут помешать сосредоточиться ребенку или спровоцировать его на истерику. Для детей с РАС очень важно знать, чего их ждет. Часто их тревожность связанна с неизвестностью, поэтому введение новых элементов или видов нагрузки в рамках программы следует вводить определенным образом. Перед каждым занятием педагог и ребенок вместе составляют визуальное расписание на специальной магнитной доске с помощью карточек, изображающих и называющих определенный этап занятия: “Приветствие”, “Разминка", “Упражнение змейка на ковре”, “Перерыв” и другие этапы тренировки. Каждый этап сопровождается соответствующей картинкой или фотографией, где изображен предмет или действие. Так ребенок будет знать, что он четко следует плану, что впереди нет ничего страшного или опасного. Каждое занятие должно начинаться одинаково, следуя плану, а нововведения должны появляться поступательно, начиная с подготовительных упражнений.

Как было выявлено ранее, дети с РАС часто имеют низкий уровень физической выносливости и для его повышения необходимо постепенно прибавлять нагрузку. Чтобы не перенапрячь ребенка, важно начинать с минимальных нагрузок, обязательно прерываясь на непродолжительный отдых. В зоне отдыха желательно организовать сиденье, доступ к питьевой воде, также положительный эффект могут оказать игрушки-антистресс, чтобы снять напряжения ребенка. После эффективной паузы у обучающегося будет больше сил на продолжение занятия, и нагрузку можно слегка увеличить. Важно наблюдать за состоянием каждого ребенка индивидуально - если один быстро привыкает к нагрузкам, то другой ребенок может не выдержать напора и сорвется в истерику. 
Для детей с PAC очень эффективен визуальный способ подачи информации. С помощью специального приложения, а также видео-уроков, можно проиллюстрировать теоретические основы, которые изучаются в рамках курса. Также в дополнение к обучению родители могут просматривать дома фильмы или клипы о катании на роликах, чтобы сформировать у ребенка представление об этом виде спорта. Особенно эффективным методом обучения является самомоделирование - это когда ребенок выполняет упражнение, его снимают на видео, и в следующий раз показывают видео, чтобы напомнить об элементе, а также чтобы ребенок понял, что от него хотят. Этот способ особенно действует при работе с неговорящими детьми.

Упражнения и игры в рамках программы в основном построены на:

- проработке коммуникативных навыков;

- демонстрации физического упражнения;

- отработке физического упражнения с физической подсказкой;

- отработке физического упражнения с вербальной подсказкой;

- поощрении.

В рамках программы также сконцентрировано внимание на сопоставлении ребенком с РАС названия элемента с самим упражнением.

Как было выяснено ранее, для детей с РАС важно соблюдать порядок, что также касается и названий элементов. Если элемент “фонарик” первый раз был назван именно так, то инструкция “сделай ногами кружок”, или “нарисуй роликами овал” будет проигнорирована, ребенок просто не поймет, что от него требуется. Здесь, если обычные дети могут провести аналогию и понять, какое задание имеется ввиду, то для детей с РАС важно произносить инструкции четко, громко и без лишних дополнений.

Таким образом, программа реабилитации с помощью роллер спорта для детей с РАС разработана с учетом всех факторов, необходимых для эффективной реабилитации детей.

После проведенной коррекционной работы, по итогам проведения контрольного среза было выявлено, что у детей наблюдались улучшения в сфере использования средств коммуникации и социального взаимодействия. Практически все дети, классифицированные ранее как дети с высоким уровнем проявления аутистических признаком, приобрели навыки, характерные для среднего уровня. Дети, владеющие навыками на среднем уровне, также повысили свои показатели, стали использовать чаще речевые конструкции в верном контексте, стали лучше воспринимать и выполнять 
инструкции, меньше стали “отключаться" от внешнего мира. Не все дети смогли приобрести навыки, связанные с самостоятельным обслуживанием, активным использованием речи и навыки самостоятельного владения новым видом спорта, однако, у всех детей наблюдается положительная динамика в улучшении тех или иных показателей. Многие дети стали целенаправленно обращаться с просьбами к педагогу или родителю, отвечать на вопросы как вербальным, так и невербальным способом, расширился запас социальных жестов.

Таким образом, в процессе реализации программы были выявлены следующие критерии, обеспечивающие эффективную реабилитацию:

- визуальная демонстрация (в том числе видеомоделирование);

- использование физических подсказок;

- использование четких и не перегруженных инструкций;

- строгое соблюдение плана занятий;

- устранение всех возможных внешних раздражителей;

- обучение методом перехода от простого к сложному;

- многократное повторение изучаемого элемента/навыка;

- разделение сложных действий на короткие подводящие действия;

- поощрение желаемого поведения и игнорирование нежелательного;

- соблюдение алгоритма “визуальная демонстрация, инструкция + физическая подсказка, подкрепление";

- акцентирование на индивидуальных целях и потребностях конкретного ребенка.

При работе с детьми с РАС важно учитывать все индивидуальные особенности ребенка, а также положение семьи. Чем больше педагог знает о ребенке, тем эффективнее будет составлена программа занятий, а значит, можно будет добиться впечатляющих результатов в развитии навыков ребенка. Тренировки и занятия для детей с РАС всегда несут комплексный характер, прорабатывая и коммуникационные способности, и физические навыки, а также многие другие аспекты, необходимые для успешной реабилитации. Важно ориентироваться на индивидуальные цели ребенка, на проработку тех навыков, которых не хватает именно ему. В реализации программы важно качество, а не количество усвоенных навыков (физических, социальных и др.). 
Применение педагогами разработанных методов оценки детей с РАС и критериев работы с такими детьми будет способствовать формированию коммуникативной, социальной и физической деятельности у детей младшего школьного возраста с расстройствами аутистического спектра, а также позволит более качественно реализовать программы инклюзивного образования для таких детей.

\section{Список литературы}

1. Детский аутизм и АBA: ABA (Applied Behavior Analisis) : терапия, основанная на методах прикладного анализа поведения / Роберт Шрамм ; пер. с англ. 3. Измайловой-Камар ; науч. ред. С. Анисимова.—-Екатеринбург : Рама Паблишинг, 2013. - 208 с

2. На ты с аутизмом: использование методики Floortime для развития отношений, общения и мышления. - 5-ое\Стенли Гринспен, Серена Уидер.: М.: Теревинф, 2017.-512c.

3. Довбня С., Морозова Т., Залогина А., Монова И. Дети с расстройствами аутистического спектра в детском саду и школе: практики с доказанной эффективностью. - СПб.: Сеанс, 2018. - 202 с., ил.

4. Интеграция детей с ограниченными возможностями в образовательный процесс. Начальная школа / Авт.-сост. Л. В. Годовникова, И. В. Возняк. - Волгоград: Учитель, 2011. - 87 с. 